\title{
UV Excision Repair Protein RAD23 Homolog A
}

National Cancer Institute

\section{Source}

National Cancer Institute. UV Excision Repair Protein RAD23 Homolog A. NCI Thesaurus.

Code C106252.

UV excision repair protein RAD23 homolog $\mathrm{A}$ (363 aa, $\sim 40 \mathrm{kDa}$ ) is encoded by the human RAD23A gene. This protein is involved in both DNA repair and the targeting of ubiquitinated proteins to the proteasome. 